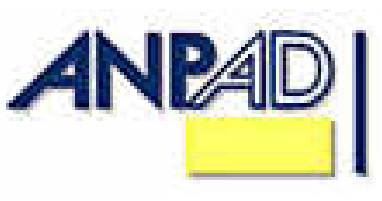

Available online at http://www.anpad.org.br/bar

\title{
How Informative Are Interest Rate Survey-based Forecasts? ${ }^{(1)}$
}

\author{
Mateus A. Feitosa * \\ E-mail address: mateus.araujo@uc3m.es \\ Universidade Carlos III de Madrid \\ Madrid, Spain.
}

\section{Benjamin M. Tabak}

E-mail address: Benjamin.Tabak@bcb.gov.br

Banco Central do Brasil; Universidade Católica de Brasília

Brasília, DF, Brazil.

\section{ABSTRACT}

This paper studies the information content of survey-based predictions for the Brazilian short-term interest rate. We perform vector autoregression analysis to test for the dynamic relationship between market expectations of interest rates and spot interest rates, and a single regression forecasting approach. Empirical results suggest that surveys may be useful in assessing market expectations (contain relevant information) and in building Central Bank credibility. Within an inflation targeting framework they are crucial in order to receive timely feedback on market sentiment regarding the conduct of monetary policy.

Key words: interest rate forecasting; short-term interest rate, survey-based predictions.

Received 11 December 2007; received in revised form 11 August 2008.

Copyright (C) 2008 Brazilian Administration Review. All rights reserved, including rights for translation. Parts of this work may be quoted without prior knowledge on the condition that the source is identified.

* Corresponding author: Mateus A. Feitosa

Department of Business Administration, Universidad Carlos III de Madrid, C/ Madrid, 126, 28903, Madrid, Spain. 


\section{INTRODUCTION}

The dynamics of interest rates have important implications for the economy and their forecasts are necessary for almost all economic activities. Participants in the financial markets require accurate forecasts of interest rates to make economic and financial decisions. These decisions have a heavy influence on aggregate-spending, which, in turn, affects real output and inflation.

In mid-1999, after moving to a floating exchange rate system, Inflation Targeting [IT] was implemented in Brazil. This new monetary framework proved to be fundamental in enhancing transparency and in guiding expectations. Additionally, evidence suggests a positive relationship between inflation targets and the credibility of monetary policy ${ }^{(2)}$.

Other studies (see Minella, 2003) indicate that the Central Bank of Brazil is concerned exclusively with inflation control, thereby avoiding the inflation-output trade-off to enhance short-term production in Brazil. This behavior is an important aspect towards the construction of credibility.

In an IT framework the main goal of the Central Bank is to provide guidance to the economy to anchor expectations regarding the future path of inflation. Therefore, it is crucial to assess market expectations in a timely fashion and check whether they are in line with the conduct of monetary policy.

With the implementation of the IT regime in Brazil the Central Bank of Brazil began to collect information from market participants using surveys, which provide information regarding market expectations on relevant economic and financial variables such as short-term interest rates (SELIC) ${ }^{(3)}$, inflation, exchange rates, GDP growth, and others. However, very little is known regarding the informational content of these survey-based market predictions. If the information content embedded in such predictions is relevant and meaningful then these surveys may be used to assess Central Bank credibility and eventually to calibrate the conduct of monetary policy.

In this paper, we study the dynamic relationship of interest rate based-survey forecasts and spot interest rates. Our results suggest that these market expectations contain useful information regarding the future evolution of interest rates and also that they may be used to gauge Central Bank credibility.

The rest of the paper will be structured as follows: in section Brief Literature Review a brief literature review is presented; section Data Description describes the data used in our estimates; section Methodology contains the methodology; in section Empirical Results we present the empirical results; in section Policy Implications the policy implications are discussed and, finally, section Final Considerations concludes.

\section{BRIEF LITERATURE REVIEW}

The market predictions for the interest rate are an important issue that has been studied for a long time, mainly in the case of the United States financial system. The studies analyze many questions, such as the directional accuracy of the predictions, the rationality of the forecasts and the quality of the methods used to forecast interest rates.

Friedman (1980) and Baghestani (2006) make an evaluation of the interest rates in the USA and both test the rationality of the forecasts. They both arrived at the same conclusion that the forecasts are not rational, i.e., they are unbiased and, in some cases, do not fully incorporate the information contained in past actual rates. Using Friedman's sample, Mishkin (1981) also tests the rationality of the forecasts and reached the opposite conclusion. The author argues that there is very little evidence in bond market data in support of the irrationality of interest rate forecasts. Jones and Roley (1983) rejected the 
joint hypotheses that forecasters form their expectations rationally and the expectations model of the term structure accurately represents equilibrium yields. However, because a joint hypothesis is tested, the precise cause of rejection cannot be determined.

Dua (1991) tests various hypotheses concerning the determinants of the three, six, and nine-month horizon term premia. He uses data on the three-month Treasury bill rate from the survey conducted by the American Statistical Association in collaboration with the National Bureau of Economic Research. His conclusion is that the term premia vary over time and are negative in some periods. They are heavily influenced by the level of interest rates and cyclical factors in addition to the level of rates. They are also influenced by Government economic policy.

Hafer, Hein and McDonald (1992) compare four different one-quarter ahead forecasts of the threemonth U.S. Treasury-bill rate from the 12-year period 1977/88. The forecasts considered are: a prediction from the futures market, a forecast derived from an implicit forward rate calculation, a survey-gathered forecast and a no-change forecast. Their main conclusion is that the futures market rate statistically dominates the other three forecasts. Another comparison of forecasting methods is made by Fauvel, Paquet and Zimmermann (1999), which concludes that despite their apparent simplicity, univariate models tend to do pretty well in practice for forecasting purposes. Similarly, their natural extension to a multivariate setting (i.e. VAR and VECM) constitutes an interesting approach for an integrated treatment of various interest rates, including both their short-term dynamics and any existing long-run relationships.

Kolb and Stekler (1998) examine three issues: is there a general agreement among analysts about the level of interest rates six months in the future; are all the forecasters equally good; are the forecasts valuable to prospective users? They conclude that there is a consensus among financial analysts and there is no significant difference in the ability of these financial analysts to predict short-term interest rates. For the last issue, the conclusion is that the forecasts were not significantly better than random walk forecasts.

Greer (2003) tests the directional accuracy of long-term interest rate forecasts. The tests are applied to the 1-year long-term bond yield issued by The Wall Street Journal's panel of economic forecasters. The author affirms that the forecasts performed modestly better than flipping a fair coin to predict the direction of change in long-term interest rates. The forecast of movements in long-term interest rates were also studied by Pesando (1981), who concluded that economic agents are not likely to succeed in forecasting short-term movements in long-term interest rates.

Following the results found by previous studies, Mitchell and Pearce (2007) concluded that market forecasts for the Treasury bill rate had a performance very similar to the random walk model, even though they found no evidence that these forecasts are biased.

Overall, we have a poor understanding of the role of market expectations (implied in surveys) on the determination of interest rates. Do forecasts collected in surveys correctly predict changes in future interest rates? How do interest rates survey based forecasts interact with spot interest rates? This paper attempts to answer these questions by focusing on the Brazilian economy, which has had an inflationtargeting framework in operation since 1999, and has collected information on market expectations employing surveys since 2001.

\section{DATA DESCRIPTION}

Data from Selic and the market forecasts in the one, three and six-month horizon were used in this paper. The data consists of the period from November, 2001 to August, 2006. Selic series were taken from Bloomberg, and the market predictions series were taken from the Central Bank of Brazil, which 
has been monitoring market consensus for the most important economic variables since 2001. In this study, we use average forecasts, and our sample has 57 observations.

Table 1 presents the descriptive statistics of the series and it shows that Selic and the forecasts for all time horizons reject the null hypothesis of following a normal distribution, despite the low values of the skewness.

\section{Table 1: Descriptive Statistics}

\begin{tabular}{ccccc}
\hline & Selic & One month & Three month & Six month \\
Mean & 19.00877 & 18.68745 & 18.05655 & 17.26463 \\
Std. Dev. & 3.254792 & 3.046300 & 2.826462 & 2.400556 \\
Skewness & 1.125748 & 1.148835 & 1.034043 & 0.963024 \\
Kurtosis & 3.426352 & 3.570575 & 3.540068 & 3.486089 \\
Jarque-Bera & $12.47114 *$ & $12.84444^{*}$ & $10.46984 *$ & $8.878380^{* *}$ \\
\hline
\end{tabular}

One, Three and Six months are survey-based forecasts for these time periods, respectively.

$*, * *$ denote rejection of the null hypothesis with $1 \%$ and $5 \%$ significance, respectively.

To test if the series are stationary, we employ the Augmented Dickey-Fuller [ADF] and the Kwiatkowski-Phillips-Schmidt-Shin [KPSS] tests. The results for Selic and the average of the Selic forecasts are shown in Table 2 and they indicate that all series are stationary. Consequently, the use of a VAR model is the appropriate method to study the dynamic relationship between these series.

Table 2: ADF and KPSS Unit Root Tests Results for the Average of the Predictions

\begin{tabular}{|c|c|c|c|c|}
\hline & \multicolumn{2}{|c|}{$\mathrm{ADF}$} & \multicolumn{2}{|c|}{$\mathrm{KPSS}^{-}$} \\
\hline & \# of lags & test statistics & Bandwidth $^{\circ}$ & LM-stat \\
\hline SELIC & 2 & $-3.985 * *$ & 6 & 0.2883 \\
\hline One-month & 4 & $-3.732 * *$ & 5 & 0.247467 \\
\hline Three-months & 4 & $-3.967 * *$ & 5 & 0.211648 \\
\hline Six-months & 4 & $-3.854 * *$ & 5 & 0.182617 \\
\hline
\end{tabular}

The relationship between Selic and the three-month horizon forecast is presented in Figure 1. It indicates that the movements of the series over time are very similar, and it appears that the forecasts' movements follow Selic's changes, indicating that there is an asymmetric relationship between the series. 
Figure 1: Relationship between Selic and the Three-month-ahead Forecast

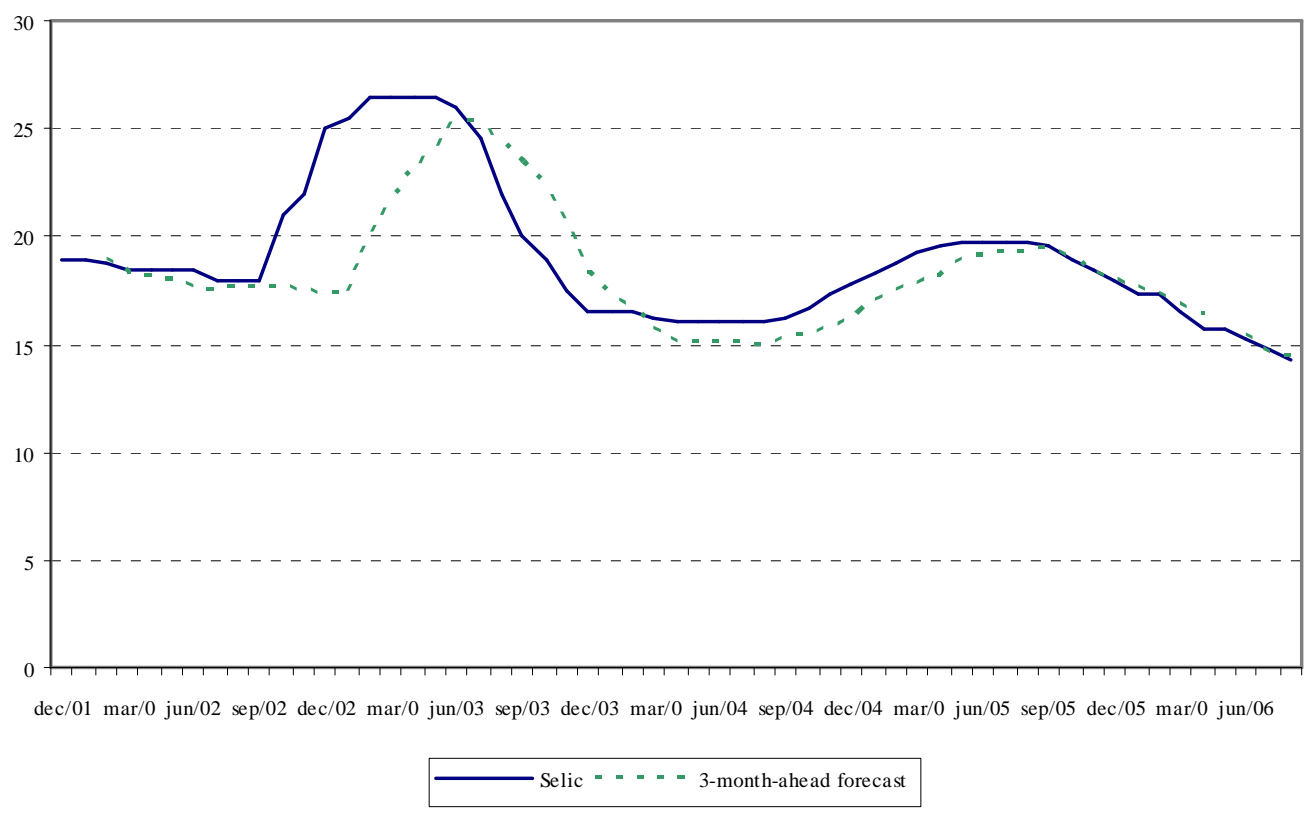

\section{METHODOLOGY}

\section{Multivariate Approach}

The use of a VAR model is a suggestive option, considering that, while the late past cannot perfectly predict future values, it does provide valuable guidance. Furthermore, VAR models have proved to be very useful tools in forecast methods ${ }^{(4)}$. Consequently we treat each variable symmetrically, and we also consider both endogenous. The VAR model used was:

$$
\begin{aligned}
& \text { Selic }_{t}=\alpha_{1}+\sum_{i=1}^{p} \alpha_{1, i} \text { Selic }_{t-i}+\sum_{i=1}^{p} \alpha_{1, i} \text { Forec }_{t-i}+\varepsilon_{1, t} \\
& \text { Forec }_{t}=\alpha_{2}+\sum_{i=1}^{p} \alpha_{2, i} \text { Selic }_{t-i}+\sum_{i=1}^{p} \alpha_{2, i} \text { Forec }_{t-i}+\varepsilon_{2, t}
\end{aligned}
$$

where Forec are the survey-based forecasts for the Selic interest rate, $p$ is the lag length used in the model, and $\varepsilon_{1}$ and $\varepsilon_{2}$ correspond to the errors of each equation, respectively. This approach is similar to the one followed by Mehra (2002), who tested for the US the predictive content of inflation surveybased forecasts.

To determine the appropriate lag length, the Schwarz Information Criterion [SIC] was employed. The SIC, rather than the Akaike Information Criterion, was selected because it imposes a larger penalty for additional coefficients. In the estimation of the VAR model, the SIC suggested 2 lags as the optimal number of lags for the one and three-month-ahead forecasts, and 4 lags for the six-monthahead forecast. Residual tests were employed with the purpose of verifying serial autocorrelation and heteroscedasticity. 


\section{Univariate Approach}

In the previous subsection we presented the framework that will be employed to study the dynamic relationship between spot interest rates and survey-based forecasts. We also test for the informational content of survey-based forecasts in a single regression approach.

The regression equation that is employed is:

Selic $_{t+j}=\alpha+\beta$ Forec $_{t, t+j}+\varepsilon_{t}$

where Selic $t+j$ is realized Selic at time $\mathrm{t}+\mathrm{j}$, and Forec $t, t+j$ is the forecast made at time $\mathrm{t}$ for period $\mathrm{t}+\mathrm{j}$. Rational forecasts would imply $\alpha=0$ and $\beta=1$. If $\alpha$ differs from zero then we have risk premiums embedded in survey-based forecasts, and if $\beta$ differs from one forecasts are biased. Values for $\beta$ larger than one imply that forecasts tend to underestimate true realizations of short-term interest rates, while $\beta$ less than one overestimate.

Since we are using monthly observations and we have three and six-month forecasts, the residuals of these predictions will have moving average (MA) terms, MA(2) and MA(5), respectively. Therefore, we employ the Newey and West (1987) corrected standard errors to make inference on parameters $\alpha$ and $\beta$.

\section{EMPIRICAL RESULTS}

\section{Multivariate Approach}

In this section, results for the VAR estimation are presented. Table 3 shows results for VAR estimation for different time horizons. These results report that all the coefficients estimated are significant at $5 \%$ or $10 \%$ significance. The only exception is in the six-month horizon, where the lagged values of the forecasts ( $\mathrm{t}-2, \mathrm{t}-3$ and $\mathrm{t}-4)$ are not significant in the determination of Selic. It is important to note that the high values of the adjusted $\mathrm{R}^{2}$ indicate that the model is well specified. 
Table 3: Var Results of the Relationship between Selic and the Survey-based Predictions

\begin{tabular}{|c|c|c|c|c|c|c|}
\hline \multirow[b]{3}{*}{ Selic(-1) } & \multicolumn{2}{|c|}{ one-month } & \multicolumn{2}{|c|}{ three-month } & \multicolumn{2}{|c|}{ six-month } \\
\hline & Selic & Forec & Selic & Forec & Selic & Forec \\
\hline & $1.176694 * *$ & $0.876593 * *$ & $1.189792 * *$ & $0.748432 * *$ & $1.258175^{* *}$ & $0.644587 * *$ \\
\hline Selic (-2) & $-0.320861 * * *$ & $-0.612198 * *$ & $-0.331082 * *$ & $-0.610565 * *$ & -0.17009 & $-0.763836^{* *}$ \\
\hline Selic $(-3)$ & & & & & $-0.647282 * *$ & $0.288238 * *$ \\
\hline Selic(-4) & & & & & $0.378047 * *$ & -0.044768 \\
\hline Forec $(-1)$ & $0.610844 * *$ & $0.941781 * *$ & $0.615958 * *$ & $1.072779 * *$ & $0.549878 * *$ & $1.354043 * *$ \\
\hline Forec $(-2)$ & $-0.534659 * *$ & $-0.270082 * *$ & $-0.531109 * *$ & $-0.305245^{* *}$ & -0.257585 & $-0.768462 * *$ \\
\hline Forec $(-3)$ & & & & & -0.04106 & $0.379797 * *$ \\
\hline Forec (-4) & & & & & -0.058486 & $-0.214714 * *$ \\
\hline $\mathrm{C}$ & $1.332864 * *$ & $1.063379 * *$ & $1.190559 * *$ & $1.580588 * *$ & 0.170493 & $1.929080 * *$ \\
\hline Adj. R-squared & 0.962725 & 0.992014 & 0.962771 & 0.988609 & 0.966253 & 0.987012 \\
\hline F-statistic & 323.8462 & 1553.782 & 311.3272 & 1042.440 & 165.6355 & 437.9623 \\
\hline Log likelihood & -46.09380 & -3.828627 & -44.16371 & -7.952474 & -38.10895 & -1.641102 \\
\hline Akaike AIC & 2.003678 & 0.346221 & 2.006682 & 0.528672 & 2.004636 & 0.452813 \\
\hline Schwarz SC & 2.193073 & 0.535615 & 2.199725 & 0.721715 & 2.358920 & 0.807096 \\
\hline Test & Value & p-value & Value & p-value & Value & p-value \\
\hline LM & 7.206499 & 0.1254 & 5.713072 & 0.2216 & 6.200176 & 0.1847 \\
\hline JB & 206.5881 & 0.0000 & 207.2309 & 0.0000 & 102.6337 & 0.0000 \\
\hline White & 32.15931 & 0.1231 & 26.77530 & 0.3150 & 47.50373 & 0.4931 \\
\hline
\end{tabular}

$* *$ and $* * *$ indicate the significance at the $5 \%$ and $10 \%$ level, respectively.

The number of lags was selected using The Schwarz information criterion.

LM indicates the lagrangian multiplier test, JB the Jarque-Bera statistics and White the White Heteroscedasticity test.

In the LM test it was used 3, 3 and 5 lags, respectively.

It is worth mentioning that the LM test did not reject the null hypothesis that there is no serial autocorrelation for all time horizons. Additionally, there is a lack of heteroscedasticity, based on the White test and the Jarque-Bera test rejects the null hypothesis that the data follow a normal distribution.

The variance decomposition results are reported in Table 4 for all the time ranges, and they indicate that Selic explains a major part of its error variance. For the relationship between Selic and the onemonth-ahead forecast, Selic explains near $100 \%$ of its error variance. On the other hand, the forecasts are extremely affected by Selic. The forecast error variance is, in the first periods, explained by its own past values, but as the period increases, forecast error variance is mostly explained by Selic. 
Table 4: Variance Decomposition of Selic and the Average of the One, Three and Six-month Horizon Forecasts (Survey-based)

\begin{tabular}{|c|c|c|c|c|c|c|}
\hline \multicolumn{7}{|c|}{ Variance decomposition of Selic } \\
\hline \multirow[t]{2}{*}{ Period } & \multicolumn{2}{|c|}{ one-month forecast } & \multicolumn{2}{|c|}{ three-month forecast } & \multicolumn{2}{|c|}{ six-month forecast } \\
\hline & Selic & Forecast & Selic & Forecast & Selic & Forecast \\
\hline 1 & 100.0000 & 0.000000 & 100.0000 & 0.000000 & 100.0000 & 0.000000 \\
\hline 2 & 97.88526 & 2.114744 & 97.02771 & 2.972294 & 97.72751 & 2.272490 \\
\hline 3 & 97.49213 & 2.507874 & 95.76706 & 4.232945 & 94.59899 & 5.401013 \\
\hline 4 & 97.24237 & 2.757635 & 94.89667 & 5.103331 & 90.42064 & 9.579364 \\
\hline 5 & 97.26540 & 2.734595 & 94.49381 & 5.506192 & 87.51658 & 12.48342 \\
\hline 6 & 97.36897 & 2.631026 & 94.33431 & 5.665688 & 85.06424 & 14.93576 \\
\hline 7 & 97.51137 & 2.488625 & 94.32987 & 5.670127 & 83.82439 & 16.17561 \\
\hline 8 & 97.65158 & 2.348421 & 94.40755 & 5.592449 & 83.09674 & 16.90326 \\
\hline 9 & 97.76728 & 2.232722 & 94.51469 & 5.485306 & 82.93300 & 17.06700 \\
\hline 10 & 97.84178 & 2.158224 & 94.60621 & 5.393790 & 82.92325 & 17.07675 \\
\hline 11 & 97.86543 & 2.134567 & 94.64544 & 5.354561 & 83.01840 & 16.98160 \\
\hline 12 & 97.83729 & 2.162711 & 94.60999 & 5.390012 & 83.05480 & 16.94520 \\
\hline 13 & 97.76706 & 2.232942 & 94.49944 & 5.500564 & 82.97965 & 17.02035 \\
\hline 14 & 97.67378 & 2.326216 & 94.33670 & 5.663300 & 82.77030 & 17.22970 \\
\hline 15 & 97.58003 & 2.419974 & 94.15850 & 5.841500 & 82.43520 & 17.56480 \\
\hline \multicolumn{7}{|c|}{ Variance decomposition of forecasts } \\
\hline Period & \multicolumn{2}{|c|}{ one-month forecast } & \multicolumn{2}{|c|}{ three-months forecast } & \multicolumn{2}{|c|}{ six-months forecast } \\
\hline 1 & 18.87834 & 81.12166 & 7.483230 & 92.51677 & 2.514133 & 97.48587 \\
\hline 2 & 79.75540 & 20.24460 & 63.99316 & 36.00684 & 48.80950 & 51.19050 \\
\hline 3 & 86.87736 & 13.12264 & 74.49516 & 25.50484 & 61.59084 & 38.40916 \\
\hline 4 & 90.56222 & 9.437778 & 79.88502 & 20.11498 & 68.85500 & 31.14500 \\
\hline 5 & 92.41356 & 7.586439 & 82.71250 & 17.28750 & 70.75269 & 29.24731 \\
\hline 6 & 93.57836 & 6.421640 & 84.46104 & 15.53896 & 72.22286 & 27.77714 \\
\hline 7 & 94.33701 & 5.662986 & 85.58020 & 14.41980 & 72.72544 & 27.27456 \\
\hline 8 & 94.84457 & 5.155428 & 86.29651 & 13.70349 & 73.18133 & 26.81867 \\
\hline 9 & 95.16832 & 4.831683 & 86.71879 & 13.28121 & 73.43126 & 26.56874 \\
\hline 10 & 95.34752 & 4.652485 & 86.91574 & 13.08426 & 73.66186 & 26.33814 \\
\hline 11 & 95.41011 & 4.589891 & 86.94824 & 13.05176 & 73.73705 & 26.26295 \\
\hline 12 & 95.38556 & 4.614444 & 86.88646 & 13.11354 & 73.67107 & 26.32893 \\
\hline 13 & 95.30957 & 4.690431 & 86.80633 & 13.19367 & 73.49611 & 26.50389 \\
\hline 14 & 95.22098 & 4.779024 & 86.76953 & 13.23047 & 73.25932 & 26.74068 \\
\hline 15 & 95.15249 & 4.847509 & 86.80432 & 13.19568 & 73.06519 & 26.93481 \\
\hline
\end{tabular}

For the factorization the Cholesky Decomposition was used.

The number of lags used in the VAR were selected using the Schwarz Information Criterion.

Granger causality tests (Granger, 1996) for Selic and the predictions are shown in Table 5, and they indicate that, for shorter time horizons, either the effect of Selic on the survey-based predictions or the effect of forecasts on Selic are significant. Thus, causality is bidirectional: Selic affects the forecasts, and vice-versa. These findings are consistent with the conventional wisdom that the short-term interest rate values in the late past have a big influence on the predictions of the market, and the Central Bank is influenced by several variables, including market predictions on the determination of short-term interest rates. For a longer time horizon (six months), the Granger Causality test suggests that the causality is unidirectional: Selic affects the forecasts, but not the reverse. 
Table 5: Granger Causality Test among Selic and the Average of the One, Three and Six-month Horizon Forecasts

\begin{tabular}{lcc}
\hline & $\chi^{2}$ & p-value \\
\hline Selic $\rightarrow$ One-month Forecast & 14.78221 & 0.0006 \\
One-month forecast $\rightarrow$ Selic & 170.9895 & 0.0000 \\
Selic $\rightarrow$ three-month forecast & 14.33598 & 0.0008 \\
Three-month forecast $\rightarrow$ Selic & 111.6262 & 0.0000 \\
& & \\
Selic $\rightarrow$ six-month forecast & 5.236671 & 0.2639 \\
Six-months forecast $\rightarrow \rightarrow$ Selic & 82.02120 & 0.0000 \\
\hline Where the symbol $\rightarrow \rightarrow$ stands for Does not Granger-cause. &
\end{tabular}

\section{Univariate Regressions}

The results for the regression (equation 3) are reported in Table 6. The market would have a perfect prediction of Selic if the value of the $\alpha$ parameter were zero, and the value of the $\beta$ parameter were equal to one. It is interesting to note that the time range has a non neglectable influence over the estimations. The one-month-ahead forecast is very precise $(\beta=1.009)$, and as the time horizon increases, both the overestimation and the premium term increase. Additionally, in the six-month horizon forecasts, the joint hypothesis $\alpha=0$ and $\beta=1$ is rejected with $5 \%$ significance, indicating that the market predictions perform poorly for this time horizon. The results also indicate that, for the three and six-month ahead forecast, the market tends to overestimate Selic's changes.

Table 6: Relationship between Selic and the Average of the One, Three and Six-month Horizon Forecasts

\begin{tabular}{ccccccc}
\hline Forecast & $\alpha$ & $\beta$ & Adj $\mathrm{R}^{2}$ & $\mathrm{H} 0: \alpha=0$ & $\mathrm{H} 0: \beta=1$ & $\mathrm{H} 0: \alpha=0$ and $\beta=1$ \\
One-month & 0.190895 & $1.009666^{*}$ & 0.875161 & 0.024678 & 0.017079 & 3.462648 \\
& $(1.215181)$ & $(0.073964)$ & & {$[0.8752]$} & {$[0.8960]$} & {$[0.1770]$} \\
Three-month & 2.805520 & $0.892932^{*}$ & 0.541853 & 0.923509 & 0.381726 & $4.849035^{* * *}$ \\
& $(2.919394)$ & $(0.173295)$ & & {$[0.3366]$} & {$[0.5367]$} & {$[0.0885]$} \\
Six-month & $11.77720^{* *}$ & 0.415430 & 0.062121 & $6.351435^{* *}$ & $4.729635^{* *}$ & $9.056505^{* *}$ \\
& $(4.673113)$ & $(0.268796)$ & & {$[0.0117]$} & {$[0.0296]$} & {$[0.0108]$} \\
\hline
\end{tabular}

$* * * * * *$ denote rejection of the null hypothesis with $1 \%, 5 \%$ and $10 \%$ significance, respectively.

' Standard errors are provided in parentheses and p-values in brackets.

" The Newey-West correction for serial correlation was used in the tests

Figure 2 presents the evolution of the adjusted $\mathrm{R}^{2}$ estimated in regressions between the one-monthahead forecast and Selic. In this case we estimate regression (3) recursively. The regression initially estimated possesses observations from December, 2001 to April, 2004; this means that half of the observations available were used in this first regression. In each regression further estimated, one observation was added. This process was repeated until all the 57 observations were present. Figure 2 indicates that the adjusted $\mathrm{R}^{2}$ has a smooth increase over time. The same figure was plotted for the regression between Selic and the three and six-month-ahead forecast, and the graphs are very similar to the one obtained for the one-month-ahead forecast. 
Figure 2: Adjusted R-squared Evolution

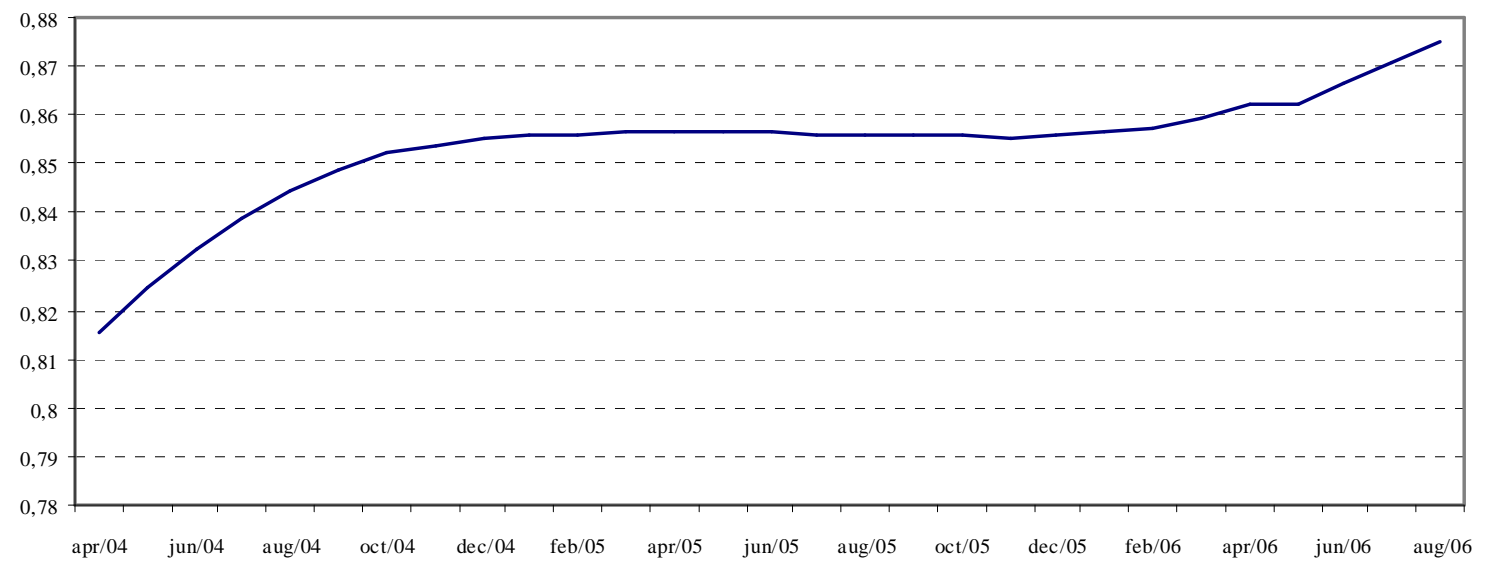

The $\mathrm{R}^{2}$ variation was calculated ${ }^{(5)}$ in order to compare how the predictable portion of Selic varies as the number of observations increase. The results found for the one, three and six-month horizon were, respectively, $7.1 \%, 44.7 \%$ and $999.19 \%$, indicating that the poor performance of longer time horizon forecasts may be due to lack of a longer time series.

We also estimate equation (3) using the Generalized Method of Moments [GMM], where it was used as an instrument the survey based predictions in the t-1 period. The results reported in table 7 indicate that there is a small qualitative difference between the results found using the OLS and the GMM. The results indicate that the market overestimates Selic in all time horizons, and not only in the 3 and 6month-ahead. Additionally, the term premium is more expressive using the GMM. For the 6-monthahead forecast, the null hypothesis $\alpha=0$ and $\beta=1$ is rejected with $1 \%$ significance.

It is interesting to note that, despite the difference among the results, the adjusted $\mathrm{R}^{2}$ have very similar values, mainly in the shorter time horizons. Finally, the J-statistic reports that the parameters used in the regression are well specified.

Table 7: Estimation Results Using Generalized Method of Moments (GMM)

\begin{tabular}{|c|c|c|c|c|c|c|c|}
\hline Forecast & $\alpha$ & $\beta$ & $\operatorname{Adj} R^{2}$ & H0: $\alpha=0$ & $\mathrm{H} 0: \beta=1$ & $\mathrm{H} 0: \alpha=0$ and $\beta=1$ & J-stat \\
\hline One month & $\begin{array}{c}1.595732 \\
(1.314787)\end{array}$ & $\begin{array}{l}0.935450 * \\
(0.074259)\end{array}$ & 0.867663 & $\begin{array}{l}1.473021 \\
{[0.2249]}\end{array}$ & $\begin{array}{c}0.755600 \\
{[0.3847]}\end{array}$ & $\begin{array}{c}4.257107 \\
{[0.1190]}\end{array}$ & $5.78 \mathrm{E}-31$ \\
\hline Three-month & $\begin{array}{c}5.933554 \\
(3.067404)\end{array}$ & $\begin{array}{l}0.723968 * \\
(0.173986)\end{array}$ & 0.515871 & $\begin{array}{c}3.741862 * * * \\
{[0.0531]}\end{array}$ & $\begin{array}{c}2.517047 \\
{[0.1126]}\end{array}$ & $\begin{array}{c}6.755358 * * \\
{[0.0341]}\end{array}$ & $1.45 \mathrm{E}-31$ \\
\hline Six-month & $\begin{array}{l}16.06075^{*} \\
(4.513689)\end{array}$ & $\begin{array}{c}0.171007 \\
(0.247491)\end{array}$ & 0.033745 & $\begin{array}{c}12.66100^{*} \\
{[0.0004]}\end{array}$ & $\begin{array}{c}11.21977 * \\
{[0.0008]}\end{array}$ & $\begin{array}{c}13.19353 * \\
{[0.0014]}\end{array}$ & $6.91 \mathrm{E}-30$ \\
\hline
\end{tabular}

\section{Forecast Comparison}

We compared the forecasting accuracy of survey-based expectations of Selic interest rates with econometric models and a Random Walk [RW] model.

The econometric models used are AR (1), where 120 observations were available and in order to determine the sample, two methods were used: the moving window method and the recursive. The moving window approach is one that bases its estimates on the most recent set of past measurements. 
Amato and Laubach (2000) suggest that forecasts of goal variables, such as interest rates and inflation, can help central banks achieve their goals and make them more accountable to the public. They defend the point of view that forecasts are valuable tools to evaluate monetary policy because of the lag response of goal variables to monetary policy.

Another important reason to follow market expectations is the possibility of inflation scare, i.e., unusual increases in inflation expectations, where macroeconomic stabilization can be affected. Orphanides and Williams (2005) affirm that it is essential to anchor private inflation expectations for successful monetary policy. They conclude that learning-induced inflation expectations perform an important role on financial stability.

This paper shows that the market forecasts for Brazilian short-term interest rates are a valuable referential of whether monetary policy is been correctly conducted. The results state that, mainly in short time horizons, market forecasts are very accurate. Additionally, the Granger causality test reports that market expectations are strongly affected by Selic in all time horizons, suggesting that monetary policy has a strong influence over market expectations. These results support the idea that forecasts can be used as a tool for an evaluation of the Central Bank's policy.

This influence of monetary policy over survey-base forecasts may be due to an increase in the Central Bank's credibility. This credibility composes the base of the IT regime.

A central bank is credible if the public believes that the monetary authority will do what it says. For the establishment of credibility, the transparency of monetary policy actions is fundamental. As reported by Lyziak, Mackiewicz and Stanislawska (2007, p. 2), "transparency is a multidimensional phenomenon, which involves not only the issue of the Central Bank releasing adequate information in terms of its quantity and quality, but also a correct interpretation of the released information by the public". To this end, guiding correct signals back to the financial market can prevent currency crises ${ }^{(6)}$.

Bauer, Eisenbeis, Waggoner and Zha (2006) indicate that since the Federal Open Market Committee [FOMC] began releasing statements after each meeting, forecasts by individuals have become more synchronized, implying a possible increase in FOMC transparency.

Analyzing the specific case of Turkey, Telatar, Telatar and Ratti (2003) and Us (2004) conclude a stronger commitment by the Government and Central Bank with gain of credibility in order to reduce inflation is fundamental.

In 1999, Brazil adopted the Inflation-Targeting [IT] framework. In this case, the success of IT depends on the construction of credibility. Private agents should believe that the central bank will act consistently within the inflation-targeting framework. Tabak (2004) reports that the implementation of the IT framework in Brazil enhanced transparency of the conduct of monetary policy, which in its turn, reduced interest rate surprises along the term structure.

This subject was also studied by Minella, Freitas, Goldfajn and Muinhos (2003). In their paper they analyzed the first three and a half years of the IT system in Brazil. Their results show that the inflation targets have worked as an important coordinator of expectations, the Central Bank has reacted strongly to inflation expectations and that there has been a reduction in the degree of inflation persistence. They conclude that the presence of a central bank committed to the achievement of pre-announced inflation targets has worked as an important coordinator of expectations and generated a more stable inflation scenario.

Bevilacqua, Mesquita and Minella (2007) found evidence that the backward-looking component of market expectations has been ceding ground to the inflation target, evidence that this regime is gaining credibility. They also affirm that the improvement in macroeconomic fundamentals played an important role in the creation of a more predictable environment.

In this paper the variance decompositions results reported that, for all time ranges, there is a preponderance of Selic's lagged values over the variance decomposition of market expectations, while 
the opposite is not verified. These findings suggest that the lack of influence of the market over the Central Bank's decisions can be interpreted as a credible monetary policy adopted in Brazil.

Thus, we can conclude that the IT framework adopted in Brazil heavily influenced control of inflation, and the mechanisms used to make the Central Bank's actions credible were well comprehended and absorbed by the public.

\section{FINAL CONSIDERATIONS}

This paper analyzes the market predictions for the Brazilian short-term interest rate. For this purpose, we used a VAR model between Selic and the survey-based predictions in the one, three and six-month horizon, and regressions among the predictions and Selic were estimated. We utilized predictions of different time horizons to determine whether time has influence over the predictions or not.

Returning to the questions initially formulated, we can conclude that the interaction between Selic and the forecasts vary over time. For shorter time horizons, there is a mutual influence among the series: the Central Bank takes the market's forecasts into consideration, and the market is strongly influenced by Selic. For a longer time horizon, the influence of Selic over the market is still strong, but the role of the market's predictions on the decisions of the Central Bank decreases.

The high influence of Selic over market forecasts indicates that market agents seem to take the Central Bank's reports into consideration. This result suggests that forecasts for Brazilian short-term interest rates can be used as a tool for an evaluation of monetary policy. The important role of forecasts on monetary policy may be due to increased Central Bank credibility, that since the implementation of the IT regime in Brazil, in 1999, it has adopted a transparent policy, aiming to reduce the market's doubts concerning monetary policy.

When analyzing the accuracy of the survey-based predictions, we can affirm that for all time horizons the market predicts correctly the direction of changes of Selic, but these forecasts are accurate only in short time intervals. For the longer time horizon studied (6 months), the joint hypothesis that the term premium $(\alpha)$ is equal to zero and the parameter $\beta$ is equal to one is rejected with $5 \%$ significance. Thus, we can conclude that the predictions tend to get less precise as the time range increases.

An interesting extension of this paper would be to analyze how the IT regime affects the markets' predictions for other variables, such as GDP and the price index. Thus, the credibility of monetary policy would be tested in an expanded structure.

Another useful future research is to investigate the role of macroeconomic variables, including output growth and money growth, on the determination of the short-term interest rate.

\section{NOTES}

\footnotetext{
${ }^{1}$ Benjamin M. Tabak gratefully acknowledges financial support from CNPQ Foundation. The opinions expressed in this paper are those of the authors and do not necessarily reflect those of Central Bank of Brazil.

${ }^{2}$ See Bogdanski, J., Tombini, A. A., \& Werlang, S. R. C. (2000). Implementing inflation targeting in Brazil [Working Paper Series 1]. Central Bank of Brazil. Brasilia, DF, Brasil., and Fachada, P. (2001). Inflation targeting in Brazil: reviewing two years of monetary policy [Working Paper Series 25]. Central Bank of Brazil. Brasilia, DF, Brasil, for a discussion about inflation targeting in Brazil.
} 
${ }^{3}$ In Brazil, the short-term interest rate, Selic, is determined by the Monetary Policy Committee (COPOM). Selic is the Brazilian shot-term interest rate because it is used in inter-bank operations and, therefore, determines the whole spectrum of long-term interest rates. Inasmuch, Selic is considered a floor for the interests paid by banks in the deposits, and, based on it, banks decide how much they will charge in loans for companies and individuals. Selic is a system for custody issued by the Brazilian Treasury and the Central Bank. By means of this system, the monetary authorities set the interest rate for secondary market benchmark.

${ }^{4}$ See Lo, W-C., Fung, H-G., \& Morse, J. N. (1995). A note on Euroyen and domestic yen interest rates. Journal of Banking and Finance, 19(7), 1309-1321, Webb, R. H. (1984). Vector autoregression as a tool for forecast evaluation. Economic Review, (Q I), 3-11, Stock, J. H., \& Watson, M. W. (2001). Vector autoregressions. The Journal of Economic Perspective, 15(4), 101-115, and Engsted, T. (1995). Does the long-term interest rate predict future inflation? A multi-country analysis. The Review of Economics and Statistics, 77(1), 42-54 for examples of the use of VAR models in forecasts.

${ }^{5}$ The equation $\Delta \mathrm{R}^{2}=\frac{\mathrm{R}^{2} \text { last }-\mathrm{R}^{2} \text { beginning }}{\left(\frac{\mathrm{R}^{2}{ }_{\text {last }}+\mathrm{R}^{2} \text { beginning }}{2}\right)}$ was used for estimate the adjusted $\mathrm{R}^{2}$ variation.

${ }^{6}$ See Lam, M. C-H. (2001). Herd behaviour and interest rate defence. Journal of Policy Modeling, 24(2), 181-193 for an analysis of government policies to the prevention of crises.

\section{REFERENCES}

Amato, J. D., \& Laubach, T. (2000). The role of forecasts in monetary policy. Economic Review, (Q II), 21-32.

Baghestani, H. (2006). An evaluation of the professional forecasts of U.S. long-term interest rates. Review of Financial Economics, 15(2), 177-191.

Bauer, A., Eisenbeis, R. A., Waggoner, D. F., \& Zha, T. (2006). Transparency, expectations, and forecasts. Economic Review, (Q I), 1-25.

Bernanke, B., \& Woodford, M. (1997). Inflation forecasts and monetary policy. Journal of Money Credit and Banking, 29(4), 653-684.

Bevilacqua, A. S., Mesquita, M., \& Minella, A. (2007). Brazil: taming inflation expectaions [Working Paper Series 129], Central Bank of Brazil. Brasília, DF, Brazil.

Diebold, F., \& Mariano, R., (1995). Comparing predictive accuracy. Journal of Business and Economic Statistics, 13(3), 253-263.

Dua, P. (1991). Survey evidence on the term structure of interest rates. Journal of Economics and Business, 4(2), 133-142.

Fauvel, Y., Paquet, A., \& Zimmermann, C. (1999). A survey on interest rate forecasting [Working Paper no 1999-087]. Université du Québec à Montréal. Montréal, Québec, Canada.

Friedman, B. M. (1980). Survey evidence on the 'rationality' of interest rate expectations. Journal of Monetary Economics, 6(4), 453-465.

Granger, C. W. J. (1996). Can we improve the perceived quality of economic forecasts? Journal of Applied Econometrics, 11(5), 455-473

Greer, M. (2003). Directional accuracy tests of long-term interest rate forecast. Journal of Forecasting, 19(2), 291-298.

Hafer, R. W., Hein. S. E., \& McDonald, S. S. (1992). Market and survey forecasts of the three-month treasury-bill rates. Journal of Business, 65(1), 123-138. 
Jones V, D. S., \& Roley, V. (1983). Rational expectations and the expectations model of the term structure: A test using weekly data. Journal of Monetary Economics, 12(3), 453-465.

Kolb, R. A., \& Stekler, H. O. (1998). How well do analysts forecast interest rates? Journal of Forecasting, 15(5), 385-394.

Lyziak, T., Mackiewicz, J., \& Stanislawska, E. (2007). Central bank transparency and credibility: the case of Poland, 1998-2004. European Journal of Political Economy, 23(1), 67-87.

Mehra, Y. P. (2002). Survey measures of expected inflation: revisiting the issues of predictive content and rationality. Economic Quaterly, 88(3), 17-36.

Minella, A. (2003). Monetary policy and inflation in Brazil (1975-2000): a VAR estimation. Revista Brasileira de Economia, 57(3), 605-635.

Minella, A., Freitas, P. S. de, Goldfajn, I., \& Muinhos, M. K. (2003). Inflation targeting in Brazil: constructing credibility under exchange rate volatility. Journal of International Money and Finance, 22(7), 1015-1040.

Mishkin, S. F. (1981). Are market forecasts rational? The American Economic Review, 71(3), 295-306.

Mitchell, K., \& Pearce D. K. (2007). Professional forecasts of interest rates and exchange rates: evidence from the Wall Street Journal's panel of economists. Journal of Macroeconomic, 29(4), 840-854.

Newey, W. K., \& West, K. D. (1987). A simple, positive semi-definite, heteroskedasticity and autocorrelation consistent covariance matrix. Econometrica, 55(3), 703-708.

Orphanides, A., \& Williams, J. C. (2005). Inflation scares and forecast-based monetary policy. Review of Economic Dynamics, 8(2), 498-527.

Pesando, J. E. (1981). On forecasting interest rates: An efficient markets perspective. Journal of Monetary Economics, 8(3), 305-318.

Tabak, B. M. (2004). A note on the effects of monetary policy surprises on the Brazilian term structure of interest rates. Journal of Policy Modeling, 26(3), 283-287.

Telatar, E., Telatar, F., \& Ratti, R. A. (2003). On the predictive power of the term structure of interest rates for future inflation changes in the presence of political instability: the Turkish economy. Journal of Policy Modeling, 25(9), 931-946.

Us, V. (2004). Inflation dynamics and monetary policy strategy: some prospects for the Turkish economy. Journal of Policy Modeling, 26(8-9), 1003-1013. 